\title{
The Industrial Convergence, Integration, or Syncretic Between China and the Countries along the B\&R: Conceptual and Empirical Clarification
}

\author{
William Sheng Liu* \\ Research Centre for International Trade and Economics / \\ Institute for Africa Studies, \\ Guangdong University of Foreign Studies \\ Guangzhou, China \\ *wsl_economics@126.com
}

\author{
Bei-Bei Wu \\ School of International Trade and Economics \\ University of International Business and Economic \\ Beijing, China
}

\begin{abstract}
This paper attempts to make conceptual and empirical clarifications between industrial convergence, integration and syncretic which are often used interchangeably in the current literature and few studies have clarified. Conceptually, this paper clarifies the concepts and defines that industrial integration is a process, while industrial convergence is an outcome and industrial syncretic, an effect. Employing the data spanning the period of 2005-2017 and covering China and other 64 countries which joined the Belt and Road $(B \& R)$ at the first round in 2014, this paper constructed different indexes to measure the development of industrial convergence, integration and syncretic and distinguish the varieties between those three concepts. The empirical results support the conceptual clarification and indicate that there are differences between the development of industrial convergence, integration and syncretic. Industrial convergence may not lead to industrial integration or syncretic, and vice versa. These findings are instructive as it would provide richer policy implications and also enlighten future research.
\end{abstract}

Keywords-convergence, integration, syncretic, China, the belt and road $(B \& R)$

\section{INTRODUCTION}

Since the Belt and Road (B\&R) Initiative was proposed, the relationship between China and the countries along the $B \& R$ has been analyzed extensively. In summary, the current literature analyzed the $\mathrm{B} \& \mathrm{R}$ construction mainly from potential of economic development, arguing that it is conducive to China's economic integration with Asia, Europe and Africa and realize emerging economies' collectivization; from energy, agricultural, industrial and technological cooperation, arguing that it is effective to promote the co-development through forming complementary and benign competition among the countries; and from the influencing factors that include cultural and institutional differences, religion, race, geopolitics and other issues. However, although it is widely argued in the literature that construction of the B\&R would enhance social, cultural and technological cooperation and particularly economical connections between the countries, few studies have made conceptual and empirical clarification between industrial convergence, integration and syncretic, as the current studies exhibited, which are often used interchangeably. The distinction across those three concepts is important, as the empirical results of this paper imply that industrial convergence does not inevitably bring about industrial integration or syncretic, and vise verse. A country needs to employ different modes to get full benefit from the $\mathrm{B} \& \mathrm{R}$ construction.

\section{CONCEPTUAL ClarificAtion}

Industrial convergence, integration and syncretic are a kind of new economic phenomenon accompanied by technological change and diffusion, which began to greatly attract public attentions after the successfully held 'Harvard Forum' and 'Berkeley Conference'. From the technical perspective, industrial convergence, integration and syncretic are to blur the boundaries between industries. By sharing common knowledge and technological foundation, different industries can promote the integration of common technology, thus significantly affecting or changing the process of product, competition and value creation in each other [1].

From the perspective of inter-industry relations, taking computer, broadcasting and printing industries as the sample, Negrouponte is an early scholar utilizing the intersecting and overlapping circles to define industrial convergence [2]. That is, industrial convergence is defined as the overlap of industry alliance, technology network platform and market. Convergence can also be defined as to shrink or disappear industrial boundaries, or to merge several independent markets by removing entry barriers between different market boundaries [2]. More specifically, based on the theoretical framework of industrial convergence process, the process of industrial convergence needs to go through four stages, namely, from scientific research convergence to technology, service convergence and finally industrial convergence [3].

Although scholars tried different angles to make definitions, it has been seen that those three concepts are used interchangeably. Convergence, integration and syncretic/ agglomeration have inter-connections between each other, but reveal different aspects of industrial development. According to the definitions of a dictionary, convergence is the fact that

This research was supported by the National Social Science Fund [Grant number 17BJL115]. 
solving the problems of insufficient local materials and information asymmetry. In contrast, integration refers to the action or process of combining two or more things in an effective way, and syncretic means combining different religions, cultures, or ideas [4]. That is, industrial convergence may refer to the tendency of the similar industrial structure distribution or codevelopment among different regions due to the similarity of resource endowment and geographical proximity. This is shown by the high similarity of the proportion and growth rate between industries.

Differently, industrial integration refers to the process or way that divides and combines production between different parties, and this would be more effective and efficient than working independently. According to $\mathrm{H}-\mathrm{O}$ theory[5], two countries are able to establish a specialized division of labor in terms of each factor endowment, and then gradually form an industrial chain to complement each other. This is conducive to combine resources and give play to comparative advantages of each, internalize transaction costs, reduce trade barriers, and finally realize high efficiency and low-cost development of both countries.

On the contrary, industrial syncretic means combining or clustering a large number of enterprises in order to pursue economies of scale and scope. Enterprise agglomeration can produce corresponding advantages of the community. This would facilitate knowledge diffusion among firms and help an individual in the community to gain competitive advantages. In turn, the development of individuals would promote the expansion and growth of the whole agglomeration area. In other words, agglomerative effectiveness is to cluster the interrelated production with an area up to a certain scale, so that enterprises can obtain cost savings and promote the growth of each other to form the so-called 'oasis effect' [6].

Being further to analyze the connection of those three concepts, as the above definitions are explained by the previous studies, industrial integration is a process, while industrial convergence is an outcome and industrial syncretic, an effect. They connect with each other, but it doesn't mean that one necessarily leads to another. For example, an increase in industrial convergence might lead to industrial integration when countries have complementary industrial structures, or might not when having competing structures. Differently, if business links between two regions/countries are strengthened up to a certain degree, industrial convergence would cause syncretic effects or industrial agglomeration, no matter whether they have complementary or competing for industrial structures [7]. In contrast, industrial integration between two countries may result in their industrial convergence, since increased production connections especially research collaboration would accelerate resource and knowledge flows, reduce risks and production costs, realize economies of scale, and finally promote their co-development. Furthermore, if industrial integration and agglomeration happen simultaneously, it would be possible to establish a multi-dimensional parallel and crossindustry cooperation network which includes specialized vertical industrial clusters as well as highly correlated horizontal clusters. This model is conducive as it is able to optimize resource allocation between regions, industries and product value chains, thus integrating global resources and

\section{EMPIRICAL EVIDENCE}

Based on the above discussion about those three concepts, this paper decides to employ Structural Similarity Index (SSI) [8] and industrial growth rates to compare the degree of industrial convergence between China and the countries along the B\&R [5]. Moreover, the economic connections are used to measure the level of industrial integration, and Spatial Gini Coefficient (SGC)[9], examine the degree of industrial syncretic/agglomeration.

The data used in empirical analysis span the period of 2005-2017 and covers 65 countries that joined the B\&R construction in the first round in 2014. Except for China, they include Singapore, Malaysia, Indonesia, Myanmar, Thailand, Laos, Cambodia, Viet Nam, Brunei, Philippine, Iran, Pakistan, Iraq, Turkey, Syria, Jordan, Lebanon, Israel, Palestine, Saudi Arabia, Yemen, Oman, United Arab Emirates, Qatar, Kuwait, Bahrain, Egypt, Greece, Cyprus, Kazakhstan, Uzbekistan, Turkmenistan, Tajikistan, Kyrgyzstan, Belarus, Azerbaijani, Armenia, Moldova, Russia, Ukraine, Georgia, Poland, Lithuania, Estonia, Latvia, Czech Republic, Slovakia, Hungary, Slovenia, Croatia, Bosnia, Herzegovina, Montenegro, Serbia, Albania, Romania, Bulgaria, Macedonia, Mongolia, India, Bangladesh, Afghanistan, Sri Lanka, Maldives, Nepal and Bhutan. The data sources are the Knoema database, World Bank Development Indicators, IMF World Economic Outlook, National Bureau of Statistics of China and Penn World Table.

Table I summarizes the results to indicate that industrial convergence, integration and syncretic cannot be used interchangeably. First, although the SSI indicates that the industrial structure of Croatia developed similarly to that of China, industrial integration between the two countries in terms of international trade has decreased especially compared to their increased ratios of trade to GDP. This may due to that the two countries have competing industrial structures.

TABLE I. EMPIRICAL RESULTS

\begin{tabular}{|c|c|c|c|}
\hline $\begin{array}{c}\text { Industrial } \\
\text { convergence }\end{array}$ & $\begin{array}{c}\text { Lead to } \\
\text { convergence }\end{array}$ & $\begin{array}{c}\text { Lead to } \\
\text { integration }\end{array}$ & $\begin{array}{c}\text { Lead to } \\
\text { syncretic }\end{array}$ \\
\hline $\begin{array}{c}\text { Industrial } \\
\text { integration }\end{array}$ & $\begin{array}{c}\text { Not the case } \\
\text { between China } \\
\text { and ASEAN }\end{array}$ & $\begin{array}{c}\text { No the case } \\
\text { between China } \\
\text { and Croatia }\end{array}$ & $\begin{array}{c}\text { No the case } \\
\text { between China } \\
\text { and Hungary }\end{array}$ \\
\hline $\begin{array}{c}\text { Industrial } \\
\text { syncretic }\end{array}$ & $\begin{array}{c}\text { Not find } \\
\text { evidence }\end{array}$ & $\begin{array}{c}\text { No the case } \\
\text { between China } \\
\text { and Singapore }\end{array}$ \\
\hline
\end{tabular}

Second, what happens between China and some ASEAN countries provides an example to illustrate that although industrial integration increased between them, if the level of connections is not enough to influence a country's economic direction, industrial convergence will not occur. Due to the advantages of geographical location, characteristics of economic size and limitation of factor endowment, the strategy of Singapore and Malaysia is not to rely on a single country for international connections, thereby reducing a single country's 
imitated country like China achieved great success in economic

influence on its development. Third, the SSI shows that the industrial structure of China and Hungary is becoming more similar, but the SGC displays that industrial agglomeration of them developed diversely. A plausible explanation is that the eastern opening strategy lets Hungary utilize multiple international factors to promote its economic development. Namely, Hungary strengthened the trading connections with Central and Eastern Europe. This is competing with China and leads to diverse industrial agglomeration. Fourth, to examine the results of China and Singapore finds that industrial integration and agglomeration would not happen simultaneously. This may due to that Singapore employs the development model of a small country, while the size of China pushes it to adopt the mode of developing a big country.

\section{CONCLUSION}

Although the empirical findings of this study indicate the existence of co-movement between industry convergence, integration and syncretic, the above discussions reveal that they are not the same thing and one does not necessarily lead to another. This derives several conclusions for policy makers or practitioners.

First, as the results show industrial convergence and codevelopment between the countries along the B\&R, countries and firms could join the B\&R construction to enhance industrial integration and utilize China's economic size to promote their development.

Second, countries should rely on their own development strategies, factor endowment, geographical or political advantages, coupled with opportunities in the $B \& R$ construction, to conditionally choose industrial syncretic in the primary, secondary or tertiary industry.

Third, as industrial convergence may not necessarily result in industrial integration or syncretic, countries should be based on their own characteristics to make long-term development strategies, rather than pursuing short-term interests in the construction of the $B \& R$. Hungary provides a good case to illustrate that a country is able to adopt a multidimensional development model by joining the B\&R construction and negotiating other regional FTAs simultaneously. This also suggests that a country does not need to completely imitate another's model to develop its economy, even though the development in the past.

Fourth, the results indicate that industrial integration between China and a country along the B\&R maybe not enough or not the only power to promote its industrial convergence and agglomeration. This implies that a country cannot rely on one source such as the B\&R construction to develop its economy. Singapore and Malaysia are good examples to reveal that a country is able to achieve faster development through combining geographical, cultural and diplomatic advantages, coupled with increased industrial integration with China during the $\mathrm{B} \& \mathrm{R}$ construction, to help to position domestic economic strategies. That is, the basic principle is to rely on own factor endowment and economic characteristics and make full use of international contacts to realize mutual benefits with others.

\section{ACKNOWLEDGMENT}

This research was supported by the National Social Science Fund [Grant number 17BJL115].

\section{REFERENCES}

[1] F. Fai, N. Von Tunzelmann. 'Industry-specific competencies and converging technological systems: evidence from patents', Structural Change and Economic Dynamics, 12(2), 2001, 141-170. 8.

[2] N. Negroponte, The Architecture Machine: Towards A More Human Environment. Cambridge, Mass.: MIT Press, 1970; B. Stewart, 'The media lab: inventing the future at MIT', New York: Viking Press, 1987, 62.

[3] C.S. Curran, S. Broring, J. Leker. 'Anticipating converging industries using publicly available data', Technological Forecasting \& Social Change, 77( 3), 2010, 385-395.

[4] Cambridge Dictionary, https://dictionary.cambridge.org/, accessed on 5th June, 2019.

[5] W.H. Davidson, 'Factor endowment, innovation and international trade theory', KYKLOS, 32(4), 1979, 764-774.

[6] J. Liang, S.J. Goetz, 'Technology intensity and agglomeration economies', Research Policy, 47, 2018, 1990-1995.

[7] B. Kinfemichael, A.K.M.M. Morshed, 'Convergence of labor productivity across the US states', Economic Modeling, 76, 2019, 270 280.

[8] Z. Brixiova, M. H. Morgan, A. Wörgötter, 'On the road to Euro: how synchronized is Estonia with the Euro zone?' The European Journal of Comparative Economics, 7(1), 2010, 203-227.

[9] P. Krugman, Geography and Trade, Cambridge, MA: MIT Press, 1991. 